\title{
Digital Transaction Analysis on Game Call of Duty (COD) Mobile using Apriori Algorithm
}

\author{
Rosalia Nansih Widyastuti ${ }^{1}$, Silvester Dian Handy Permana ${ }^{2}$ \\ $\left\{\right.$ nansih@trilogi.ac.id ${ }^{1}$, handy@trilogi.ac.id $\left.{ }^{2}\right\}$
}

Study Program of Management, Universitas Trilogi, Jakarta, Indonesia ${ }^{1}$, Study Program of Informatics Universitas Trilogi, Jakarta, Indonesia ${ }^{2}$

\begin{abstract}
The Call of Duty (COD) Mobile is a popular game which has reached 100 million downloads within a week after it was released in September 2019. This game earned 28 billion Rupiah in 3 days after released and many local developers want to follow the success by making similar games. Therefore, local game developers need to know the player's habit in buying virtual product. This research examines digital transaction patterns in used in Cash Point. Cash Points is the currency which used in the COD Mobile Game. Thus, we need a data collection algorithm that has better accuracy, namely the Apriori Algorithm. This algorithm analyzes transactions which often occur in the COD Mobile Game. The results of this study prove that most of the player purchase Cash Point to buy a Battle Pass and the remaining balance is saved to buy a Battle Pass in the next sessions. Utilizing a battle pass with at tractive prizes will increase player interest in buying the Cash Point.
\end{abstract}

Keywords: Call of Duty Mobile, Apriori, Cash Point, Game Developer

\section{INTRODUCTION}

In Indonesia, online games are starting to be in demand by all circles, especially on mobile devices. The ease of getting the internet and the devices that support it, is one of the factors in which online gaming is in great demand. In addition, users feel comfortable with the combination of animation, graphics, stories and sounds from the game [1]. According to Stat is ta.com, the mobile game segment in 2019 will reach 43.9 million users. There are several game genres such as MOBA, FPS, RPG, Battle Royal, etc. At the end of 2019, the most played game is Call of Duty Mobile (COD Mobile), which has the First Person Shooter (FPS) genre. Data released by sensortower.com, this game has reached 100 million downloads worldwide with revenues of 28 billion rupiah in 3 days after it was released. COD Mobile was developed by Activision Publishing, Inc. which is an American video game publisher based in Santa Monica, California.

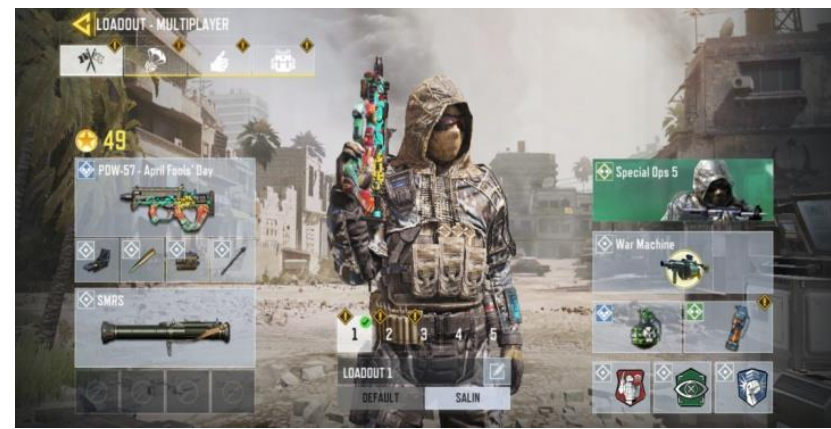

Fig.1. Overview Call of Duty Mobile 
COD Mobile is a freemium game that is downloaded for free but there are several features that can be purchased. In this game has a currency to buy virtual products, namely Cash Point. 96\% of players buy Cash Points to buy Battle Pass and Battle Pass Plus. The number of Cash Points needed to buy a Battle Pass is $440 \mathrm{CP}$ and Battle Pass Plus requires $860 \mathrm{CP}$. The virtual product that is obtained after buying a Battle Pass or Battle Pass Plus is that players get weapon skins, ghost skins, get tiers, parachute skins, etc.

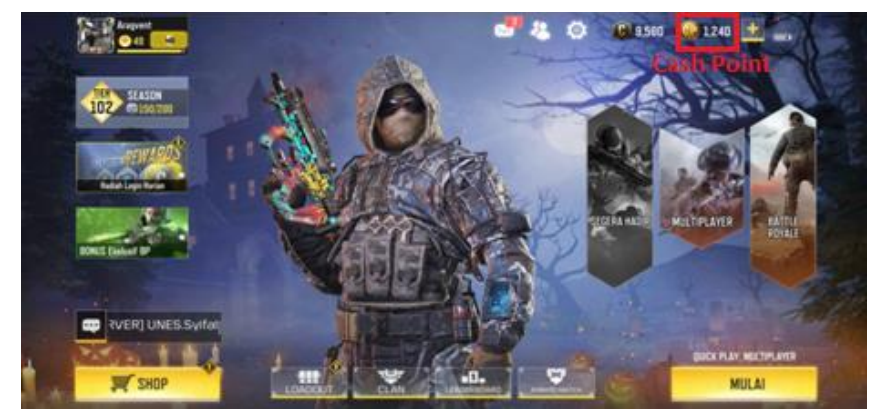

Fig.2. Cash Point COD Mobile

In purchasing, players have the desire or habit to buy virtual products obtained from Battle Pass or Battle Pass Plus. Therefore, local game developers need to know the habits of players in buying virtual products. Developers in developing the market of this game need to know the habits of players in buying virtual products to design markets according to the pattem of purchase transactions from players [2]. Market basket analysis is needed in knowing the transaction pattems of players, to look for pattems of relationships between one or more items et in a datas et using apriori alg orithm [3].

Apriori Algorithm is a data mining algorithm that is used to analyze the relationship of items in a dataset. Apriori can resolve association rules that have support and confidence nules. Support rules are items that appear together, and confidence is a tendency to buy items after the previous item [4]. The results of this study will provide a transaction pattern of purchasing Cash Points using the Apriori Algorithm.

\section{RELATED WORKS}

Data mining can be used to form pattems in predicting future events with the level of accuracy of each method used [5]. An example is predicting a shopping basket to find out an item purchase transaction pattem. In completing data mining there are association rules to determine the relationship between one item purchased with another [6]. There are 2 association rules, namely support and confidence. Support is the percentage of combination items that appear in one database, and confidence is the percentage of relationships between items [7]. Examples of as sociation rules:

$$
\text { Tea }=>\text { Sugar }[\text { support }=20 \% \text {, confidence }=50 \%]
$$

The above rules explain that $50 \%$ of customers buy tea, there is a $50 \%$ chance that customers also buy sugar. Whereas $20 \%$ support shows that tea and sugar are bought together. Apriori algorithms include types of association rules in data mining which are often us ed in shopping basket analys is to find out items that are often bought simultaneously by customers [7]. 
From the explanation above, a literature review was conducted to support the existence of this research. There are 4 literature reviews that discuss the same topic, namely market basket analys is, transaction patterns, consumer behavior.

Research conducted by Fahrul Kurniawan, 2018 [8] states that consumer activities such as buying, using and consuming are factors that can lead to a decision to buy or not. Therefore, companies or markets must know the pattern of consumers in their purchases. With a market basket analys is can determine consumer habits in shopping. The method used in this research is Apriori. This research was applied to the transaction data of Business Center (BS) at UIN Malang supermarket. The results of this study get an average trust value of $46.69 \%$ of the $1.78 \%$ support value and the resulting rules are 30 rules. The pattem of data transactions taken has a low tendency to associate because the data are not interconnected between items.

Research conducted by Nanang Riyadi, et al 2019 [9] states that e-commerce companies should promote their products optimally and efficiently. XYZ Company us es data as a form of promotion, but sales targets are not met because the promotions shown do not match the customer's buying pattem. Therefore a market basket analys is is needed to determine the customer's pattem in the transaction. The settlement method used in this study is Apriori and Weighted Moving Average (WMA) for forecasting. The results of this study indicate that Apriori has a higher accuracy higher than 130.74, and the results of the a priori have met the quality assurance software testing (SQA) and rapidminer verification is $100 \%$ with a minimum support of $2 \%$ and a minimum confidence of $90 \%$. WMA helps companies make decisions in the category of products that must be sold.

Research conducted by Srinivasa Kumar, 2018 [10] states that Cross Selling Analysis is an important tool in the retail industry. Retail store sales can be increased by arranging promotions according to buyer's purchases and determining the position of items. This study uses 5-month data from the Super Market in Trichy, Tamil Nadu. The settlement method in this study uses the Apriori algorithm. The results of this study indicate that Cross Selling Analysis using A priorican increaserevenue, but the value of support and the number of rules is relatively less.

Research conducted by Daljeet Kaur, 2017 [11] states that data mining trends have entered into supermarket analysis. Data mining cons is ts of machine leaming, artificial intelligence, database management to form transaction pattems. This study conducted a survey of data mining with association and cluster rules. With the development of supermarkets on a large scale, it is very important to build a data mining model in supermarkets for decision making.

From a review of the research conducted, it can be concluded that the Apriori algorithm can solve Market Basket Analys is problems with the aim of knowing the pattern of consumer trans actions for items purchased and the relationship of these items.

\section{RESEARCH METHOD}

First of all, to get the transaction pattern of players using cash points in the game of Call of Duty Mobile (COD Mobile), researchers gave questions to 100 respondents. Questions as ked in the form of questionnaires relate to transactions using Cash Points for purchasing content on COD Mobile. Content that can be purchased includes Battle Pass, Tier Battle Pass, Box (Session Weapon, Werewolf, Prophet Character, Ghost Character, etc.), Weapon Skin, Costume Skin, Weapon Experience Card, Save to next Battle Pass. After getting the answer data, then steps are performed as in figure 3. 


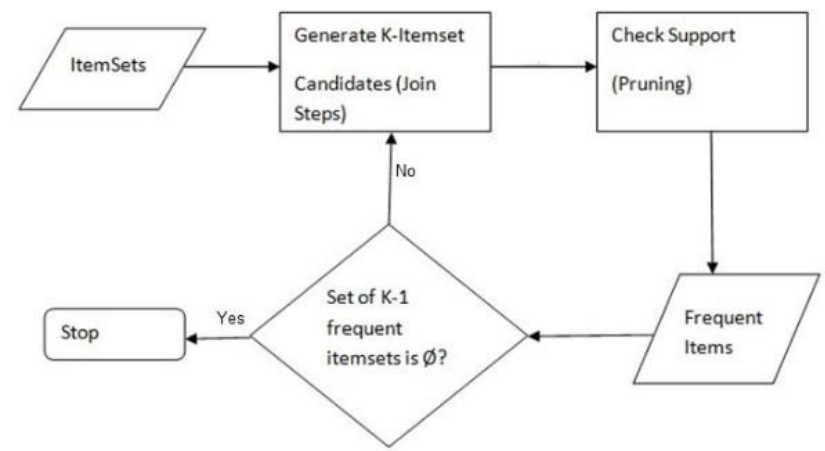

Fig.3. Step of Apriori

The completion step of the Apriori algorithm is done by iteration until there are no more kitems set that meet the minimum support. Support in association rules is the frequency with which items are bought simultaneously [12]. Before the iteration is performed, determine the minimum support as the pruning criteria. Minimum support is determined by the user of the total transactions made by players [13]. On the 1st iteration it scans the purchased itemset to produce a value above the minimum support. The scan results for 1 itemset that meets the minimum support will become frequent items. If the frequent item appears umpteenth times (Ф) according to the minimum support then the iteration stops and if not then the iteration continues [14]. The next iteration is done with 2 itemset which is combined from the previous $\mathrm{k}$-itemset and retums to the same process as the initial iteration. This condition stops when there are no more k-items et that meet the minimums upport.

\section{RESUlt AND DISCUSSION}

Before applying the Apriori algorithm to determine trans action patterns in a mobile call of duty game, it is necessary to collect data from the results of the questionnaire. The results of this questionnaire were obtained from 100 players who used cash points to purchase content. Cash Points (CP) can be purchased starting from $80 \mathrm{CP}-8000 \mathrm{CP}$, with prices starting from Rp.15,000 - Rp. 1,499,000. In purchasing, Cash Points can be done with various payment methods such as using a credit card or credit. Players who buy 400 Cash Points - 8000 will get free Cash Points. Players who top up for the first time will get a bonus in the form of an HG40Electric weapon and a Weapon Exp 500 card.

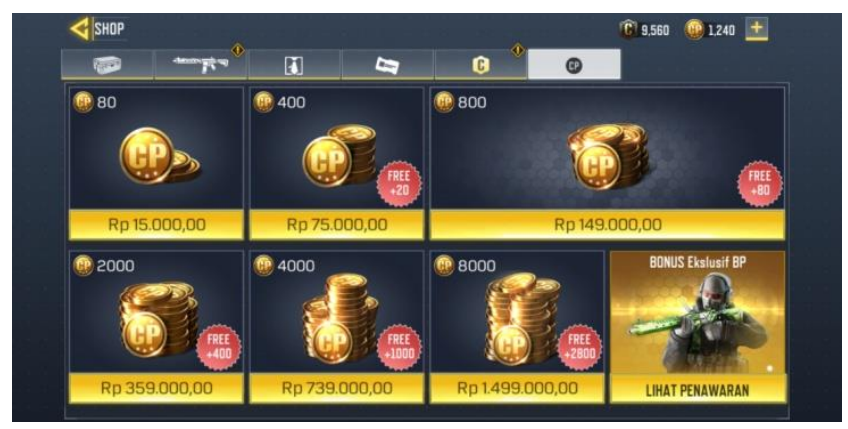

Fig.4. Cash Point 
Based on figure 4 to buy a Premium Pass, players need a minimum of $440 \mathrm{CP}$ or around Rp. 90,000. Meanwhile, to buy Premium Pass Plus, players need $860 \mathrm{CP}$ or around Rp. 165,000 .

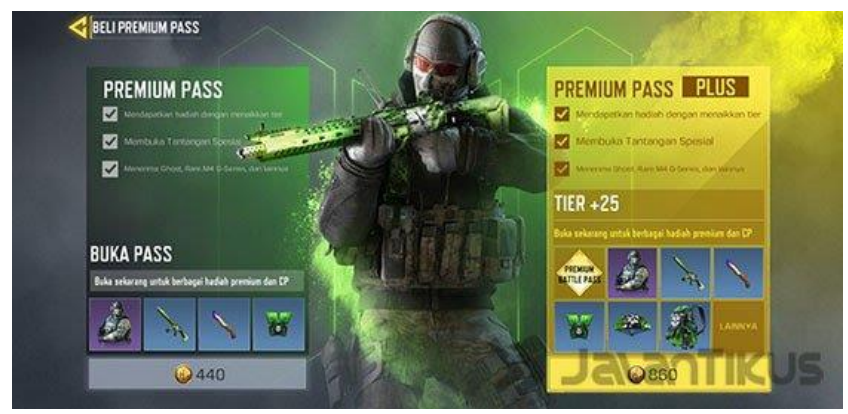

Fig.5. Premium Pass

Features obtained from this Premium Pass include: get a prize every tier ride, open the Elite Task, get the Ghost character, Rare M4-G Series and many others. While the features obtained from Premium Pass Plus include: get the Premium Pass feature, get access to tier 25, Rare Backpack G-Series, Rare wis eguy leopard spray, flas hbang, s moke and many others.

In making transaction pattems using Cash Points, researchers gave questionnaires to 100 Call of Duty Mobile players. The completed questionnaire data will be recorded as an item set as in Table 1 below.

TAB LE 1. DATA FROM 100 QUESTIONNAIRES

\begin{tabular}{|c|l|}
\hline No & \multicolumn{1}{c|}{ Item set } \\
\hline 1 & Battle Pass, Save for next session \\
\hline 2 & Battle Pass Plus, Save for next session \\
\hline 3 & Battle Pass, Buy some gun skins, Save for next session \\
\hline 4 & Battle Pass, Buy Tier \\
\hline 5 & Battle Pass Plus, Buy Tier Save for next session \\
\hline 6 & Buy Tier Only \\
\hline$\ldots$ & $\ldots$ \\
\hline 100 & Battle Pass, Buy Parachute skin. \\
\hline
\end{tabular}

Item set that have been collected will be counted as a support value to find out how many times the item appears in the database. The formula for the support value of an item can be seen in the equation 1 below:

$$
\begin{aligned}
& \operatorname{supp}(x)=\frac{\text { Number of transaction in which X appears }}{\text { Total } \text { Number of transactions }} \\
& \qquad \operatorname{supp}(B P P)=\frac{96}{100}=0.96(96 \%)
\end{aligned}
$$

The support value for Battle Pass Plus (BPP) calculated above gets $96 \%$ in 100 total transactions made by 100 players. So, Battle Pass Plus transactions are items that often appear / are bought by players with a support value reaching $96 \%$. The following is the result of support for each item set that appears, which can be seen in table 2 below. 
TAB LE 2. ITEMSET With SUPPort VALUe

\begin{tabular}{|c|l|c|}
\hline No & \multicolumn{1}{|c|}{ Item set } & Support \\
\hline 1 & Battle Pass (+Plus) & $96 \%$ \\
\hline 2 & Tier Battle Pass & $45 \%$ \\
\hline 3 & $\begin{array}{l}\text { Box (Session Weapon, Werewolf, Prophet } \\
\text { Character, Ghost Character, etc.) }\end{array}$ & $25 \%$ \\
\hline 4 & $\begin{array}{l}\text { Weapon Skin (Air Riffle, Sniper, Long Machine } \\
\text { Gun, Short Machine Gun, Shotgun, Knife, Hand } \\
\text { Bomb) }\end{array}$ & $40 \%$ \\
\hline 5 & $\begin{array}{l}\text { Costume Skin (Costume, ATV, Parachute, } \\
\text { Helicopter, etc.) }\end{array}$ & $30 \%$ \\
\hline 6 & Weapon Experience Card & $30 \%$ \\
\hline 7 & Save to next Battle Pass & $60 \%$ \\
\hline
\end{tabular}

A support value that exceeds the minimum value will be a candidate itemset solution to be combined in 2 itemset. The combination of 2 itemset can be seen in table 3 below:

TAB LE 3. 2 ITEMSET WiTH SUPPoRT VALUe

\begin{tabular}{|c|c|c|c|}
\hline No & \multicolumn{2}{|r|}{ Item set } & Support \\
\hline 1 & Battle Pass (+Plus) & Tier Battle Pass & $96 \%$ \\
\hline 2 & Battle Pass (+Plus) & 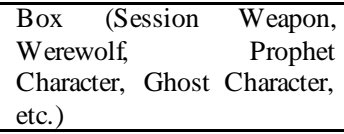 & $45 \%$ \\
\hline 3 & Battle Pass (+Plus) & $\begin{array}{l}\text { Weapon Skin (Air Riffle, } \\
\text { Sniper, Long Machine Gun, } \\
\text { Short Machine } \quad \text { Gun, } \\
\text { Shotgun, Knife, Hand } \\
\text { Bomb) }\end{array}$ & $25 \%$ \\
\hline 4 & Battle Pass (+Plus) & $\begin{array}{l}\text { Costume Skin (Costume, } \\
\text { ATV, Parachute, Helicopter, } \\
\text { etc.) }\end{array}$ & $40 \%$ \\
\hline 5 & Battle Pass (+Plus) & Weapon Experience Card & $30 \%$ \\
\hline 6 & Battle Pass (+Plus) & Save to next Battle Pass & $30 \%$ \\
\hline 7 & Tier Battle Pass & Battle Pass (+Plus) & $60 \%$ \\
\hline$\ldots$ & ... & ... & $\ldots$ \\
\hline
\end{tabular}

From the combination of the 2 itemset above an association rule can be made which then counts the support value. Here is the formula for calculating the association in equation 2 :

$$
\operatorname{Supp}(A, B)=\frac{\Sigma A \cap B}{\Sigma A} \times 100 \%
$$

Following is an example of calculating the confidence value of the association rule "Battle Pass Plus and will save for thenext session" which can be seen below

$$
\operatorname{Supp}(A, B)=\frac{96 * 78}{96} * 100 \%=78 \%
$$

The two items "Battle Pass Plus and Save Next Session" are items that are interrelated with achieving a support value of $78 \%$. The other two items that are interrelated have the value of support as in table 4 below. 
TAB Le 4. Result of Association Rules

\begin{tabular}{|c|l|c|}
\hline No & \multicolumn{1}{|c|}{ Items } & Support \\
\hline 1 & $\begin{array}{l}\text { If player buy Battle Pass (+Plus) then } \\
\text { they will keep the change }\end{array}$ & $78 \%$ \\
\hline 2 & $\begin{array}{l}\text { If player buy Battle Pass (+Plus) then } \\
\text { buy tier }\end{array}$ & $45 \%$ \\
\hline 3 & $\begin{array}{l}\text { If player buy Battle Pass (+Plus) then } \\
\text { buy weapon skin }\end{array}$ & $60 \%$ \\
\hline 4 & $\ldots$ & $\ldots$ \\
\hline
\end{tabular}

With these results it can be concluded that the Apriori algorithm can form transaction patterns using Cash Points made by COD Mobile players.

\section{CONCLUS ION}

Based on the application of the Apriori algorithm in forming transaction pattems using Cash Points, it proves that most players buy Cash Points to buy Battle Pass and the rest are saved to buy Battle Pass in the next session. Utilizing Battle Pass with attractive prizes will increase the player's interest to buy Cash Points.

\section{REFERENCES}

[1] N. Mehta, "Study to Find Patterns of Good Mobile Games,” no. December, 2018.

[2] J. Hamari, K. Alha, S. Järvelä, J. M. Kivikangas, J. Koivisto, and J. Paavilainen, "Why do players buy ingame content? An empirical study on concrete purchase motivations," Comput. Human Behav., vol. 68, pp. 538-546, 2017.

[3] M. Kaur and S. Kang, "Market Basket Analysis: Identify the Changing Trends of Market Data Using Association Rule Mining," Procedia Comput. Sci., vol. 85, no. Cms, pp. 78-85, 2016

[4] M. Hegland, "the Apriori Algorithm - a Tutorial," pp. 209-262, 2007.

[5] A. O. Adebayo and M. S. Chaubey, "Data mining classification techniques on the analysis of student's performance," Dep. Syst. Program., no. April, 2019.

[6] S. Sulova, “Association rule mining for improvement of IT project management," TEM J., vol. 7, no. 4, pp 717-722, 2018.

[7] Y. Kurnia, Y. Isharianto, Y. C. Giap, A. Hermawan, and Riki, "Study of application of data mining market basket analysis for knowing sales pattern (association of items) at the O! Fish restaurant using apriori algorithm,"J. Phys. Conf. Ser., vol. 1175, no. 1, 2019.

[8] F. Kurniawan, B. Umayah, J. Hammad, S. M. S. Nugroho, and M. Hariadi, "Market Basket Analysis to Identify Customer Behaviours by Way of Transaction Data," Knowl. Eng. Data Sci., vol. 1, no. 1, p. 20, 2017.

[9] N. Riyadi, M. F. Mulki, and R. Susanto, "Analysis of Customers Purchase Patterns of E-Commerce Transactions Using Apriori Algorithm and Sales Forecasting Analysis With Weighted Moving Average ( WMA ) Method," vol. VII, no. Vii, pp. 45-58, 2019.

[10] V. Srinivasa Kumar, R. Renganathan, C. VijayaBanu, and I. Ramya, "Consumer buying pattern analysis using apriori association rule," Int. J. Pure Appl. Math, vol. 119, no. Special Issue 7C, pp. 2341-2349, 2018.

[11] P. Deepa, “Data mining in CRM - a Survey,” Int. J. Comput. Intell. Res., vol. 13, no. 2, pp. 144-146, 2017.

[12] L. Tianbiao and H. Andreas, "Apriori-based diagnostical analysis of passings in the football game," Proc. 2016 IEEE Int. Conf. Big Data Anal. ICBDA 2016, pp. 2-5, 2016.

[13] G. S. Gayathri, "Performance Comparison of Apriori, Eclat and Fp-Growth Algorithm for Association Rule Learning," Int. J. Comput. Sci. Mob. Comput., vol. 6, no. 2, pp. 81-89, 2017.

[14] P. R. Gaikwad, S. D. Kamble, N. V. Thakur, and A. S. Patharkar, "Evaluation of Apriori Algorithm on Retail Market Transactional Database to get Frequent Itemsets," Proc. Second Int. Conf. Res. Intell. Comput. Eng., vol. 10, no. June, pp. 187-192, 2017. 